\title{
The Effects of Use of Average Instead of Daily Weather Data in Crop Growth Simulation Models
}

\author{
Sanderine Nonhebel \\ Department of Theoretical Production Ecology, Agricultural University. \\ POB 430, 6700 AK Wageningen, The Netherlands
}

(Received 2 July 1992; accepted 3 March 1993)

\begin{abstract}
Development and use of crop growth simulation models has increased in the last decades. Most crop growth models require daily weather data as input values. These data are not easy to obtain and therefore in many studies daily data are generated. or average values are used as input data for these models. In crop growth models non-linear relations often occur. Thus the simulation result with average data can be different from the average result with daily data. In this study the effects of using average weather data on simulated potential and water-limited yields were investigated with a spring wheat crop growth model. It was expected that deviation in simulation results was related to the variability of the weather. Therefore effects were studied for sites in three different climates: temperate maritime, mediterrancan and humid tropical. Variability of the weather during the growing season on these sites was quantified. Intuitively the weather in the mediterranean and humid tropical climates is far more constant than the weather in the temperate maritime climates. However, for all locations the variability of the weather daring the growing season was nearly the same. The explanation for this unexpected result was found in the fact that on all sites crops were grown in that part of the year in which it raihs. The existence of dry and wet days during the growing season causes a large day-to-day variation in veather. For all sites an overestimation of the simulated potential yield of 5-15\% was found as a result of using average weather data. For water-limited production the use of average data resulted in overestimation of pield in the liet conditions and underestimation of yield in dry conditions (up to 50\%).
\end{abstract}




\section{INTRODUCTION}

In recent decades the quantitative approach to crop growth has increased dramatically, resulting in the development of crop growth simulation models by various research groups in the world (Whisler et al., 1986). These models simulate crop growth and development under specified conditions and vary in background and structure. Crop growth is strongly influenced by weather conditions. In crop growth simulation models vital effects of weather conditions on crop growth processes are therefore described and weather data are important input data. Currently, for major crops like wheat, maize, etc. well developed crop growth simulation models exist (Ritchie \& Otter, 1984; Jones \& Kiniry, 1986; van Keulen \& Seligman, 1987; Spitters et al., 1989). In general these models operate with a time interval of 1 day and require daily weather data as input.

The overall effect of weather condition's on crop production is rather ambiguous. The effect of, for instance, high radiation levels at high temperatures can differ considerably from the effect at low temperatures. In studies involving the effect of weather conditions on crop yields, simulation models can serve as a tool since weather-crop growth relations are quantified in them. In the last years several studies have been published in which crop growth models were used to quantify growing conditions of crops. Examples are studies with respect to production possibilities in various regions of the world (van Keulen \& de Milliano, 1984; Hodges et al., 1987; van Keulen et al., 1987; Aggarwal \& Penning de Vries, 1989; van Diepen et al., 1990; Lopez-Tirado \& Jones, 1991), or on the effects of climate change on crop production (Wilks, 1988; Adams et al., 1990; Cooter, 1990; Jansen, 1990; Nonhebel, 1993a). When existing crop growth models are used for such large scale type of research, problems often occur with respect to availability of required input data. Daily weather data are seldom available, therefore in land evaluation studies weather data are generated from average values or averages are used (van Keulen \& de Milliano, 1984; Aggarwal \& Penning de Vries, 1989; van Diepen et al., 1990; Lopez-Tirado \& Jones, 1991). Because weathercrop growth relations in models are often non-linear, simulation results with average input data can deviate from average simulation results with daily data. The use of crop growth models in this large scale type of research is likely to increase in the future; it is therefore important to analyze the effects of using average weather data on the simulation results of these models.

It is expected that deviation in results is related to the variability of the weather. When weather is constant, the average value will not deviate 
from the daily values and the simulation result will be the same. When large variations in weather exist the deviation from the daily value can be large, causing deviations in simulation results, so the effect of using averages is likely to vary with climate. To investigate the magnitude of this climate effect the simulation runs were made with data from sites in three different climates: Wageningen in The Netherlands (temperate maritime climate); Migda in Israel (mediterranean climate); and Los Baños in the Philippines in the humid tropics. The choice for these sites was determined by the fact that only from these sites were daily weather data over many years available at the department.

The effects of using average weather data as input were studied for a spring wheat crop growth simulation model.

\section{CLIMATE AND AGRICULTURAL PRACTISES ON LOCATIONS STUDIED}

\section{The Netherlands}

In The Netherlands average air temperature varies from $1{ }^{\circ} \mathrm{C}$ in January to $17^{\circ} \mathrm{C}$ in July and August. Precipitation (mostly from frontal depressions, Können, 1983) is distributed homogeneously over the year, with an average of $60-70 \mathrm{~mm} / \mathrm{month}$. Large differences in total annual precipitation may occur $(600-1200 \mathrm{~mm}$, Buishand \& Velds, 1980). Global variation varies from $2 \mathrm{MJ} / \mathrm{m}^{2} / \mathrm{d}$ in winter to $17 \mathrm{MJ} / \mathrm{m}^{2} / \mathrm{d}$ in summer (Können, 1983). Large differences exist in radiation levels on successive days (Nonhebel, 1993b). Daylength on the longest day is $17 \mathrm{~h}$. Relative humidity of the air is rather constant over the year (70\%). Average wind speed is $4-5 \mathrm{~m} / \mathrm{s}$, short periods with high wind speeds (gales) occur between October and April (Können, 1983).

In The Netherlands spring wheat is sown in March and harvested in August. The average yield is 6 ton/ha (de Jong, 1986). Only in extreme dry years (total precipitation less than $600 \mathrm{~mm} / \mathrm{year}$ ) do spring wheat crops suffer from water shortage (Nonhebel, 1993a,b).

\section{Israel}

Migda is located in the northern Negev. In this region precipitation occurs during the winter period $(60 \%$ of the annual precipitation is concentrated in December and January). Average rainfall is $250 \mathrm{~mm} / \mathrm{year}$, but large annual variation exists (50-450 mm/year) (van Keulen, 1975). 
Precipitation falls in showers of $10-30 \mathrm{~mm}$. Average air temperatures in January are $13^{\circ} \mathrm{C}$ increasing up to $27^{\circ} \mathrm{C}$ in August. Daylength on the longest day is $14 \mathrm{~h}$. Radiation increases from $11 \mathrm{MJ} / \mathrm{m}^{2} / \mathrm{d}$ in December to $27 \mathrm{MJ} / \mathrm{m}^{2} / \mathrm{d}$ in August. Relative humidity is low $(40-60 \%)$ and the average wind speed is $2 \mathrm{~m} / \mathrm{s}$ (Taha et al., 1981).

In Israel wheat is sown November/December, when the winter rains start, and harvested in May. Water is the main limiting factor and yields are strongly determined by the amount of precipitation during the growing season. Yields in Migda vary between 0.5 and 3 ton/ha under rainfed conditions (van Keulen \& Seligman, 1987).

\section{Philippines}

The Philippines are located in the tropical oceans, with average water temperatures of about $27^{\circ} \mathrm{C}$. Therefore the annual variation in air temperature is very small $\left(24-28^{\circ} \mathrm{C}\right)$. With respect to the precipitation, this area is dependent on the monsoon. Hence there are distinct dry and wet seasons. Most of the precipitation occurs in July-November with average amounts of $100 \mathrm{~mm} /$ month in this season, often in tropical showers of over $50 \mathrm{~mm}$. In the dry season the radiation levels are higher than in the wet season $\left(20 \mathrm{MJ} / \mathrm{m}^{2} / \mathrm{d}\right.$ in dry season, $15 \mathrm{MJ} / \mathrm{m}^{2} / \mathrm{d}$ in wet season; Flores \& Balagot, 1969; Oldeman \& Frère, 1982). Since the Philippines are situated near the equator the annual variation in radiation is small (daylength on longest day is 13 hours). Relative humidity of the air is high $(80 \%)$ and average wind speed is low $(2 \mathrm{~m} / \mathrm{s})$, but since the area is frequently visited by tropical typhoons large deviations of this average occur.

Spring wheat is not a common crop in the Philippines, this area is mainly orientated on rice growing. Some research is done on growing wheat as a second crop after rice. In those cases wheat is sown in November/December and harvested in March (Aggarwal et al., 1987). The growing season is very short due to the high air temperatures, yields are therefore low (2-3 ton/ha).

\section{MATERIAL AND METHODS}

\section{Weather data}

Daily weather data were available for Wageningen (lat. $52^{\circ} \mathrm{N}$, long. $5^{\circ} \mathrm{E}$ ) from 1954 to 1987, for Los Baños (lat. 14 ${ }^{\circ} \mathrm{N}$, long. $121^{\circ} \mathrm{E}$ ) from 1959 to 1984 and for Migda (lat. $31^{\circ} \mathrm{N}$, long. $34^{\circ}$ E) from 1962 to 1983. The 
data sets contained daily data on minimum air temperature $\left({ }^{\circ} \mathrm{C}\right)$, maximum air temperature $\left({ }^{\circ} \mathrm{C}\right)$, total global radiation $\left(\mathrm{MJ} / \mathrm{m}^{2} / \mathrm{d}\right)$, total precipitation $(\mathrm{mm})$, early morning vapour pressure $(\mathrm{mb})$ and average wind speed $(\mathrm{m} / \mathrm{s})$. Data over complete years were available from Wageningen and Los Baños, while only weather data for the growing season (September-May) were available for Migda. All data in the sets were checked by hand and the values of missing data were replaced by estimates. When data on temperature, global radiation and precipitation were missing for more than 1 week the complete year was discarded (1964-5, 1967-8 in Migda). When data on vapour pressure and wind speed were missing, average values were used to replace missing data (Nonhebel, 1993b). The effects of the use of average values over (i) 10 days, (ii) one month and (iii) a complete growing season on the simulation results were studied. The effects of using averages over several years (climatic averages) based on daily values, 10-day averages, monthly averages and seasonal values on the simulation result were also investigated.

Average weather data were derived from the daily weather data sets, For each variable the average value per month was calculated. When these averages were used as input data for the crop growth simulation model, it was assumed the average values occurred on the 15th of every month and that on days in between the value of the variable could be derived by linear interpolation. For precipitation this method implies that the total precipitation over a month is averaged over 30 days and hence it rains every day. This contrasts with the actual situation in which there are dry and wet days. The same method was applied for the averages over 10 days, but then the average values were expected to occur at day 5 of the interval. The seasonal average was calculated by averaging the daily weather from the 180 days after sowing date on the three sites. Use of these averages implied that the weather was the same on all days of the growing season.

The climatic averages were derived from the sets with daily and averaged data. In the set with climatic data based in daily values the global radiation on January 1 st is the average global radiation of all January 1 sts from the daily data set. So the set with climatic data based on daily data contained 365 days of averaged weather (Table 1). In the set with climatic data based on monthly values, the global radiation in January in the averaged radiation from all January's in the set with monthly averages. The size of the data sets used for Wageningen is given in Table 1. For Migda averages were only calculated for the growing season.

To quantify the variation in weather at the three sites, the average deviation ( $a v d e v)$ from the daily values was calculated for each weather 
TABLE 1

The Size of the Data Sets for Wageningen.

\begin{tabular}{|c|c|c|c|}
\hline data set & Number of data & Composed of & \\
\hline Daily data & $74460=34$ Years & $\times 365$ Days & $\times 6$ Variable \\
\hline 10 day averages & $7344=34$ Years & $\times 36 \times 10$ Days & $\times 6$ Variables \\
\hline Monthly averages & $2448=34$ Years & $\times 12$ Months & $\times 6$ Variables \\
\hline Season averages & $204=34$ Years & $\times 1$ Scason & $\times 6$ Variables \\
\hline Climate based on days & $2190=$ & 365 Days & $\times 6$ Variabl \\
\hline Climate based on 10 days & $216=$ & $36 \times 10$ Days & $\times 6$ Variable \\
\hline Climate based on months & $72=$ & 12 Months & $\times 6$ Variables \\
\hline Climate based on seasons & $6=$ & 1 Scason & $\times 6$ Variables \\
\hline
\end{tabular}

variable for each averaging interval according to:

$$
a v d e v=\sqrt{\frac{\sum_{i=1}^{n}\left(x_{d i}-x_{u i}\right)^{2}}{n}}
$$

in which $x_{d i}$ is the value in the original daily data set for day $i, x_{d i}$ is the value for day $i$ derived from a set with average data. This was done over all years available.

The variability of the weather differs between seasons, it will be low in the dry hot summer and higher during the wet season. The simulation result is only affected by the variability during the growing season (the model only runs from sowing till maturing of the crop). Therefore deviations were only calculated for the 180 days after start of the simulation on the three sites. So for Wageningen $n$ equals 34 (years) $\times 180$ (days) $=6120$.

\section{Simulation model}

The crop growth simulation model used is a spring wheat model based on SUCROS87 (Spitters et al., 1989). The model has been validated for present weather conditions in The Netherlands (Nonhebel, 1993a). The model simulates potential production (limited by crop characteristics, temperature and radiation but without any stress from water or nutrient shortages or pests, diseases and weeds) and/or water-limited production in which growth is also limited by water shortage (de Wit \& Penning de Vries, 1982). Nonhebel (1993h) shows that the sensitivity of this model to changes in weather variables is not the same for both production levels. Therefore the effects of using averaged weather data for both the potential and the water-limited production were studied. 

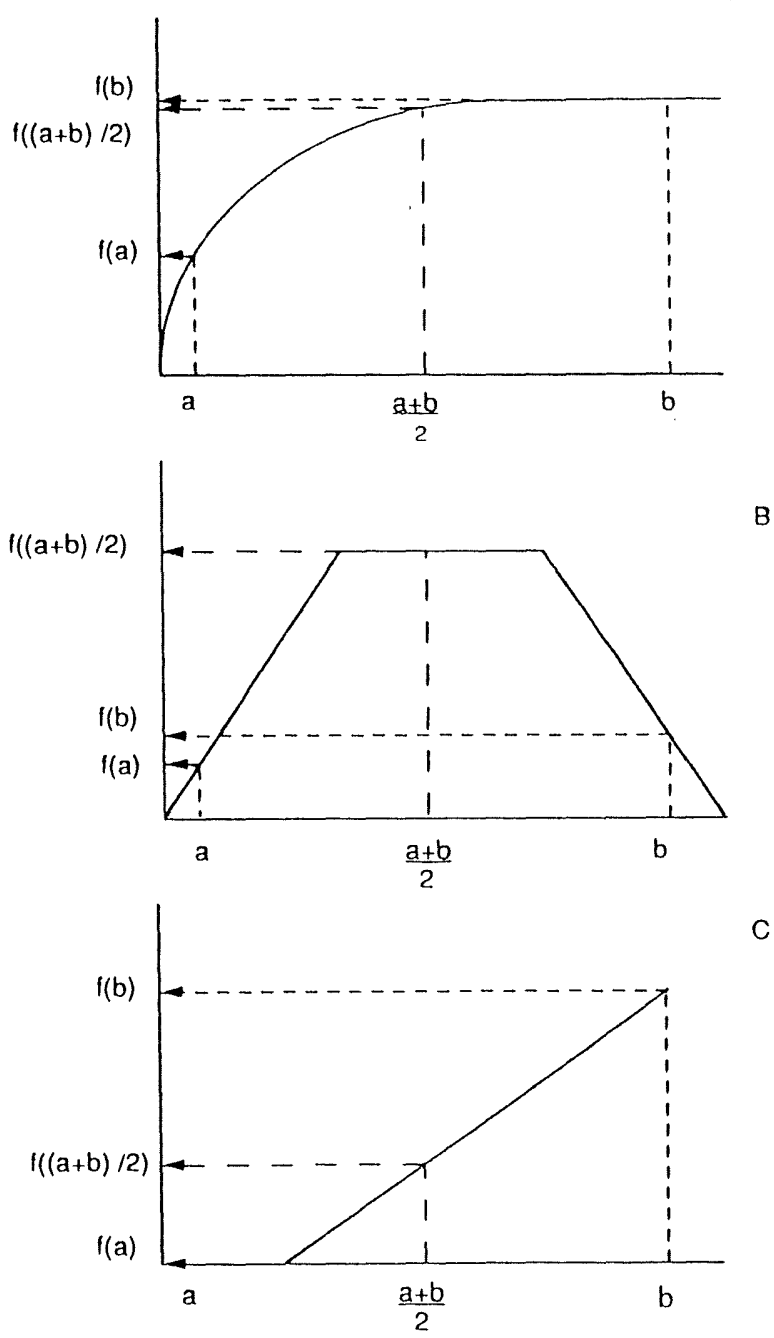

Fig. 1. Some examples of non-linear relations incorporated in the crop growth simulation model and the effect of using average input data in these functions. A, the photosynthesis-light response curve for individual leaves. B, effect of temperature on the photosynthetic rate at light saturation. $C$. effect of temperature on crop emergence rate.

The total assimilation of the crop is calculated from the photosynthesis at leaf level. The basis of the photosynthetic-light response curve for individual leaves. Since this function reaches a saturation level at high light intensities (Fig. 1A), the use of averages for global radiation results in overestimation of the photosynthesis (Nonhebel, 1993b). Both low and high temperatures have a negative effect on maximum rate of leaf photosynthesis at light saturation. When average temperatures are used these 
extremes are lost (Fig. 1b). The average temperature is therefore more favourable for crop growth than the daily temperatures. A base temperature exists for most development rates in the model. Below this temperature no development occurs. Use of average data results in temperatures always above the base temperature (Fig. Ic). Hence average data can effect development rate of the crop.

The soil is treated as a multi-layered system with 10 layers. When precipitation occurs, the first soil layer is filled up to field capacity and all excess water entering the layer drains to next layers. Soil moisture losses occur by drainage below the potential rooting zone, by crop transpiration from the rooted soil layers and by soil evaporation, mainly from the top layer. The amount of moisture in the profile is strongly determined by the distribution of the precipitation. A heavy shower (of over $100 \mathrm{~mm}$ ) causes all layers of the profile to become saturated and water drains below the rooted zone. Very light showers (of less than $2 \mathrm{~mm}$ ) will saturate only the top layer of the soil. A large part will evaporate and never reach the roots.

The initial conditions, at the start of the simulation, for the three locations were made in accordance with present agricultural practises for rainfed spring wheat. For Wageningen this implies that the crop was sown on March 11 th and that the soil profile was at field capacity; for the Migda data, sowing was set to November 1st and soil was at wilting point; and for the Los Baños data sowing was at December 1 st and soil profile was at field capacity. For the water-limited production soil characteristics from a hypothetical soil with a low available water holding capacity were used. This was done to achieve large differences in potential and water-limited production.

Eight simulation runs were made for each production level (potential and water-limited) on each site: using the set with (1) daily data; (2) 10-day averages; (3) monthly averages; and (4) seasonal averages and climatic averages over the years available based on: (5) daily data; (6) 10-day averages; (7) monthly averages; and (8) seasonal averages. Runs $1-4$ used data for 20-34 years resulting in 20-34 yields, while runs 5-8 were each for only one (average) growing season resulting in one yield per run.

\section{RESULTS}

\section{Weather data}

The data in Table 2 represent deviation of average values from daily values (eqn 1), for all weather variables on the three sites. In general the 
TABLE 2

Average Deviations from Daily Values for Six Wcather Variables (Minimum Temperature $\left(\mathrm{T}_{\min }\right)$, Maximum Temperature $\left(\mathrm{T}_{\text {max }}\right)$, Global Radiation (Rad), Precipitation (Rain), Vapour Pressure (Vap). Wind Speed (Wind)), when Averages over Several Intervals are Used. For Three Sites: Wageningen. The Netherlands; Migda, Israel; and Los Baños, Philippines.

\begin{tabular}{|c|c|c|c|c|c|c|c|}
\hline Site & Interval & $\begin{array}{l}T_{\min } \\
\left({ }^{\circ} C^{\prime}\right)\end{array}$ & $\begin{array}{l}T_{\max } \\
\left({ }^{\circ} \mathrm{C}\right)\end{array}$ & $\begin{array}{c}\operatorname{Rad} \\
\left(M . J / \mathrm{m}^{2} / d\right)\end{array}$ & $\begin{array}{l}\text { Ruin } \\
(\mathrm{mm})\end{array}$ & $\begin{array}{l}V(a p) \\
(m h)\end{array}$ & $\begin{array}{l}\text { Wind } \\
(\mathrm{m} / \mathrm{s})\end{array}$ \\
\hline Wageningen & 10 Days & $2 \cdot 7$ & 3.0 & $4 \cdot 8$ & $4 \cdot 2$ & $2 \cdot 0$ & $1 \cdot 3$ \\
\hline Wageningen & Month & $3 \cdot 1$ & 3.6 & $5 \cdot 3$ & 4.4 & $2 \cdot 3$ & 1.4 \\
\hline Wageningen & Season & $5 \cdot 0$ & 5.7 & $6 \cdot 2$ & $4 \cdot 5$ & $3 \cdot 8$ & 1.4 \\
\hline Wageningen & Climate (days) & 3.4 & $4 \cdot 0$ & $5 \cdot 6$ & $4 \cdot 5$ & $2 \cdot 5$ & $1 \cdot 5$ \\
\hline Migda & 10 Days & $2 \cdot 3$ & $3 \cdot 3$ & $3 \cdot 6$ & $5 \cdot 5$ & $2 \cdot 4$ & $0 \cdot 7$ \\
\hline Migda & Month & $2 \cdot 6$ & $3 \cdot 8$ & $3 \cdot 8$ & $5 \cdot 7$ & $2 \cdot 5$ & $0 \cdot 8$ \\
\hline Migda & Season & 3.4 & $5 \cdot 2$ & $5 \cdot 5$ & $5 \cdot 7$ & $3 \cdot 0$ & 0.8 \\
\hline Migda & Climate (days) & $2 \cdot 8$ & $4 \cdot 1$ & $4 \cdot 3$ & $5 \cdot 8$ & $2 \cdot 7$ & 0.8 \\
\hline Los Baños & 10 Days & 0.9 & $1 \cdot 3$ & $4 \cdot 0$ & $10 \cdot 3$ & $2 \cdot 2$ & $0 \cdot 4$ \\
\hline Los Baños & Month & $1 \cdot 0$ & 1.5 & 4.4 & $10 \cdot 7$ & $2 \cdot 4$ & 0.4 \\
\hline Los Banos & Season & 1.5 & $2 \cdot 7$ & $6 \cdot 0$ & $11 \cdot 3$ & $2 \cdot 9$ & 0.5 \\
\hline Los Baños & Climate (days) & $1 \cdot 2$ & 1.8 & $4 \cdot 7$ & $10 \cdot 9$ & $2 \cdot 6$ & 0.5 \\
\hline
\end{tabular}

deviation increased with increasing the length of averaged period within the season ( 10 days $<$ month $<$ season $)$. For minimum temperature, maximum temperature, radiation and vapour pressure, the deviation from the climatic average on a daily basis was smaller than the deviation from the seasonal averages. The average deviation from climatic averages based on 10-day or monthly data was the same as that calculated for averages based on daily data. The average deviation from climatic averages based on seasonal values was similar to that calculated for seasonal values in individual years.

The deviation in minimum temperature was smaller than in the maximum temperature and deviation in temperature in Los Baños was very small. Large variations in radiation levels occurred on all sites. Deviation was smallest in Migda, followed by Los Baños. The deviation in precipitation was hardly affected by length of the averaged interval. Deviations were large in Los Baños. Variations in vapour pressure were nearly the same for all sites, and deviations in wind speed were low for all sites.

\section{Simulation results}

\section{Wageningen}

Simulated potential and water-limited spring wheat yield using daily weather data from Wageningen over 34 years are shown in Fig. 2A. 

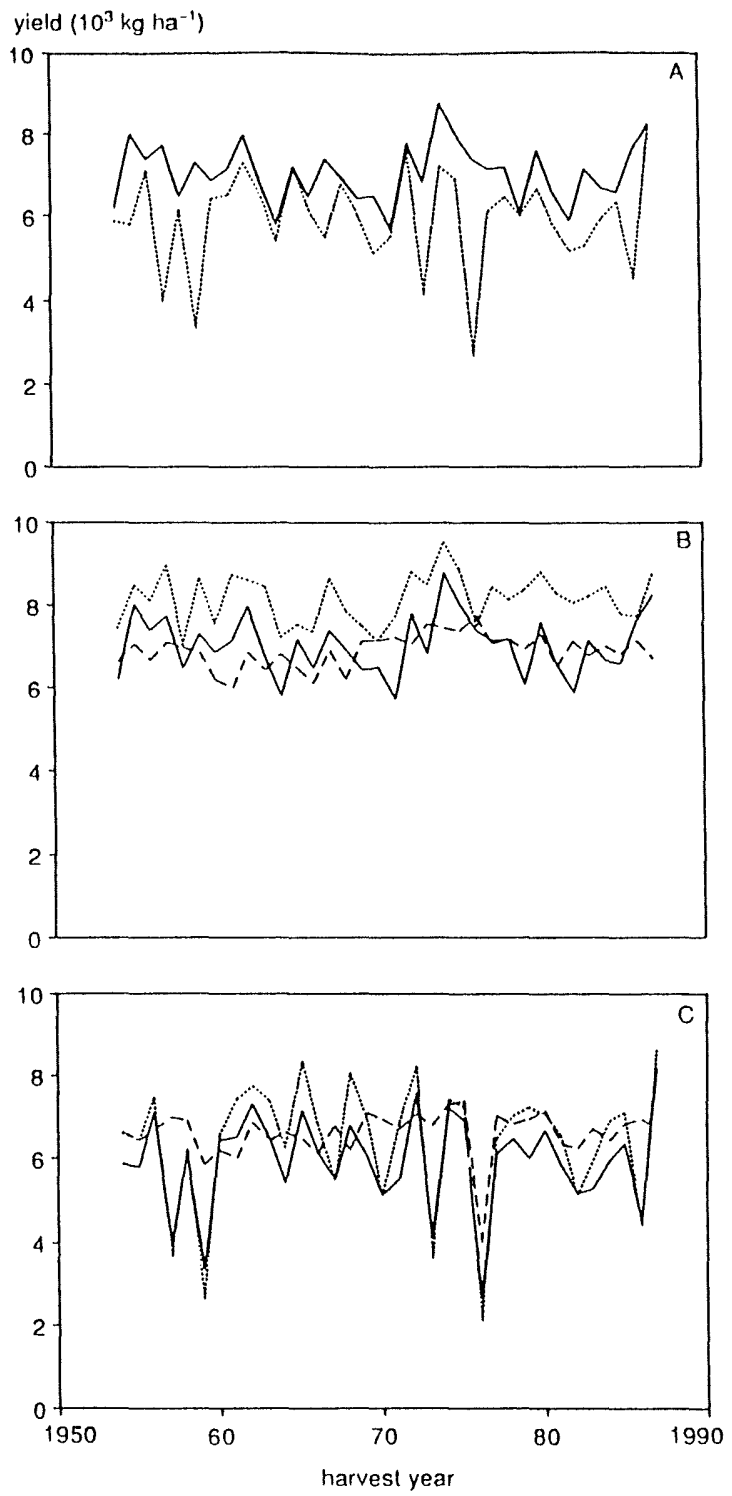

Fig. 2. Efrect of using daily and average weather data as imput on simulated potential and water-limited production in Wageningen. $\Lambda$, simulated potential (solid line) and water-limited (dotted line) production using daily weather data. B. simulated potential production using daily data (solid line) and monthly (dotted line) or seasonal averages (broken line). C, simulated water-limited production using daily data (solid line) and monthly (dotted line) or a seasonal averages (broken line). 
TABLE 3

Averaged simulated potential yield and water-limited yield and (associated standard deviations) in ton/ha, using either daily values, averages over 10 days, monthly averages and seasonal averages as input

\begin{tabular}{|c|c|c|c|c|}
\hline & $D a y$ & 10) Da!s & Month & Secason \\
\hline \multicolumn{5}{|l|}{ Potential } \\
\hline Wageningen & $7 \cdot 0(0 \cdot 7)$ & $8.0(0.6)$ & $8 \cdot 1(0 \cdot 6)$ & $6.9(0.4)$ \\
\hline Migda & $8.7(0.6)$ & $9.2(0.5)$ & $9.3(0 \cdot 6)$ & $9.0(0.5)$ \\
\hline Los Baños & $2 \cdot()(0 \cdot 4)$ & $2 \cdot 3(0 \cdot 4)$ & $2 \cdot 3(0 \cdot 4)$ & $2 \cdot 3(0 \cdot 3)$ \\
\hline \multicolumn{5}{|l|}{ Water-limited } \\
\hline Wageningen & $5.9(1 \cdot 2)$ & $6.4(1.5)$ & $6 \cdot 6(1 \cdot 3)$ & $6.6(0.6)$ \\
\hline Migda & $2.6(1.8)$ & $1.6(1.5)$ & $1.3(1 \cdot 1)$ & $1.0(0.9)$ \\
\hline Los Baños & $1.6(0.2)$ & $1.7(0.2)$ & $1.8(0.2)$ & $1.7(0.4)$ \\
\hline
\end{tabular}

Potential yield varied from 5.7 to 8.7 ton/ha, whereas water-limited yield varied from 2.6 to 8.2 ton/ha. Only in a few years $(1957,1959,1973$, 1976 and 1986) was the water-limited yield much (4 ton/ha) lower than the potential yield. In these years total annual precipitation was less than $600 \mathrm{~mm}$, through which severe water shortage existed, resulting in a limitation of the growth and reduction of the yield.

Use of averages over short periods for simulation of potential production resulted in an overestimation of the simulated yield, but betweenyear variability of the yields remained (Fig. 2B, Table 3). With the exception of a few years, simulation results with 10-day values were the same as those with monthly values. Yield was underestimated in most years when averages over complete growing seasons were used and the variability of the yields decreased. The effect of using averages for the simulation of water-limited production differed from the effect for potential production. Fig. $2 \mathrm{C}$ shows that the use of short-term averages led to underestimation of the yield in dry years and overestimation in wet years, increasing the variability of yields (Table 3 ). Use of seasonal averages resulted in overestimation of the yield in most years and a decline in variability.

Small differences in simulated yield were obtained, when climatic averages based on different intervals were used as input (Table 4). Only the simulated potential yield with climatic averages based on seasonal values was markedly lower.

\section{Migda}

The potential and water-limited production of spring wheat simulated with the daily weather data from Migda 1962-1983 (seasons 1964-65 and 1967-68 were missing) is shown in Fig. 3A. Potential production varied 
TABLE 4

Simulated Potential Yield and Water-limited Yield (ton/ha), Using Climatic Averages Based on Daily Weather Data, 10 Daty Averages. Monthly Averages and Seasonal Averages as Input.

\begin{tabular}{lcccc}
\hline & Day & I0 Da!s & Month & Season \\
\hline Potential & & & & \\
$\quad$ Wageningen & 8.1 & 8.4 & 8.4 & 7.0 \\
$\quad$ Migda & 9.0 & 9.0 & 8.9 & 8.9 \\
$\quad$ Los Baños & 2.3 & 2.4 & 2.3 & 2.3 \\
Water-limited & & & & 6.9 \\
$\quad$ Wageningen & 6.7 & 6.8 & 6.8 & 0.8 \\
Migda & 1.3 & 0.9 & 0.8 & 1.8 \\
Los Baños & 1.8 & 1.9 & 1.9 & \\
\hline
\end{tabular}

from 7.5 to 9.5 ton/ha. Simulated water-limited production was much lower $(0 \cdot 3-6 \cdot 0$ ton/ha). Severe water shortage existed in all years.

Use of averages over short periods ( 10 days or 1 month) resulted in overestimation of the potential yield by about 0.6 ton/ha in all years and variability was retained. (Fig. 3B; Table 3). Differences in simulated yields with these averages were very small. The use of seasonal averages led to overestimation of yield in most years. For water-limited production use of averages led to underestimation of yields in nearly all years and a decline in variability was observed. Averages over 10 days gave the smallest deviation (1.0 ton/ha) (Table 3). In 1967 an overestimation of the yield was obtained when averages were used (Fig. 3C).

When climatic averages were used as input, hardly any difference in simulated potential yield was found between the intervals. For waterlimited production different results were obtained: the climatic average based on daily data yielded highest (Table 4).

\section{Los Baños}

Simulated potential and water-limited yields using daily weather data from Los Baños (1959-1984) are shown in Fig. 4A. Both potential and water-limited yields were low (1-3 ton/ha) in comparison with the simulated yields with data from other locations. The difference between the two production levels was small with a maximum of 1 ton/ha.

Use of averages over short periods led to small increases in simulated potential yield (up to 0.5 ton/ha, Fig. 4B). In most years no difference existed in results with 10 -day and monthly averages. When seasonal averages were used yields were overestimated in most years. The deviation in the water-limited yield was small when averages over 10 days or 

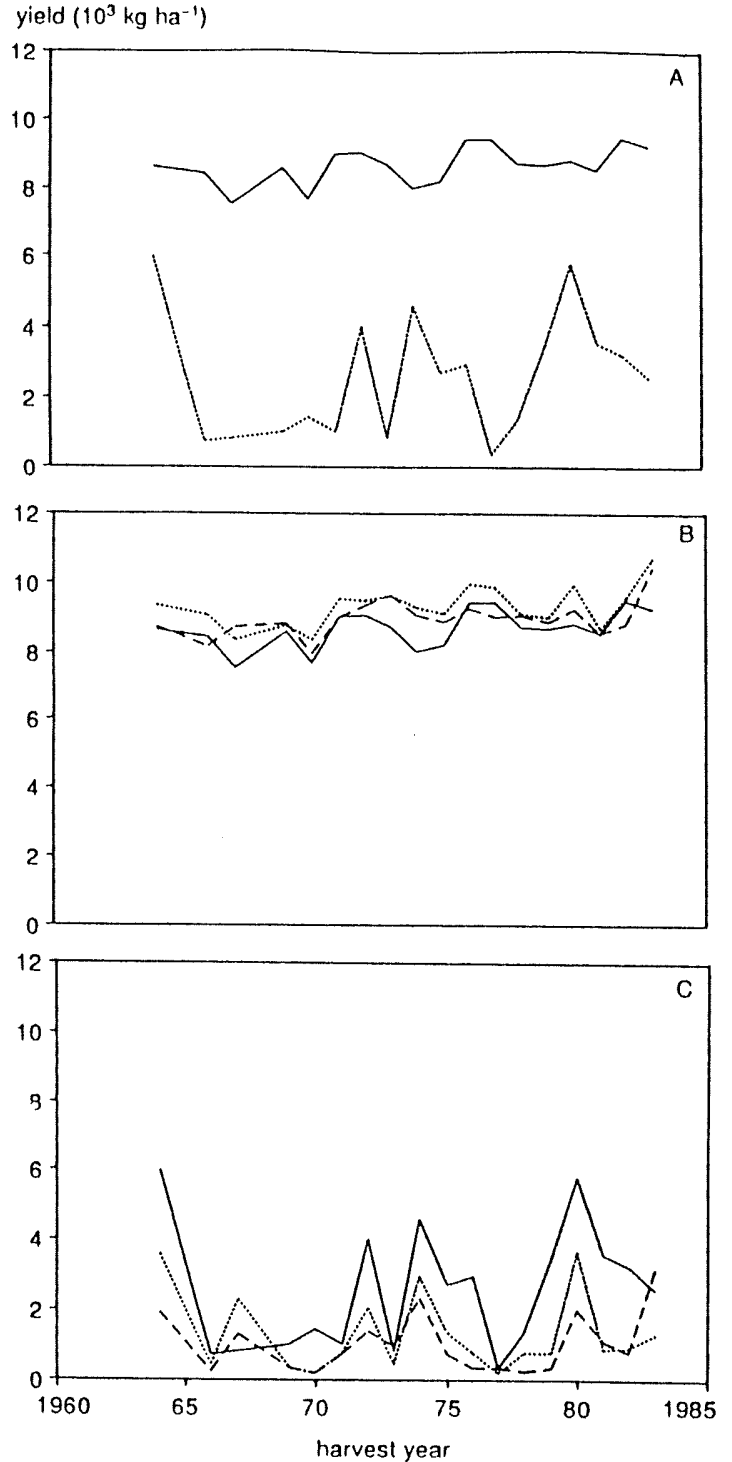

Fig. 3. Effect of using daily and average weather data as input on simulated potential and water-limited production in Migda. A, simulated potential (solid line) and water-limited (dotted line) production using daily weather data. $B$, simulated potential production using daily data (solid line) and monthly (dotted line) or seasonal averages (broken line). C, simulated water-limited production using daily data (solid line) and monthly (dotted line) or a seasonal averages (broken line). 

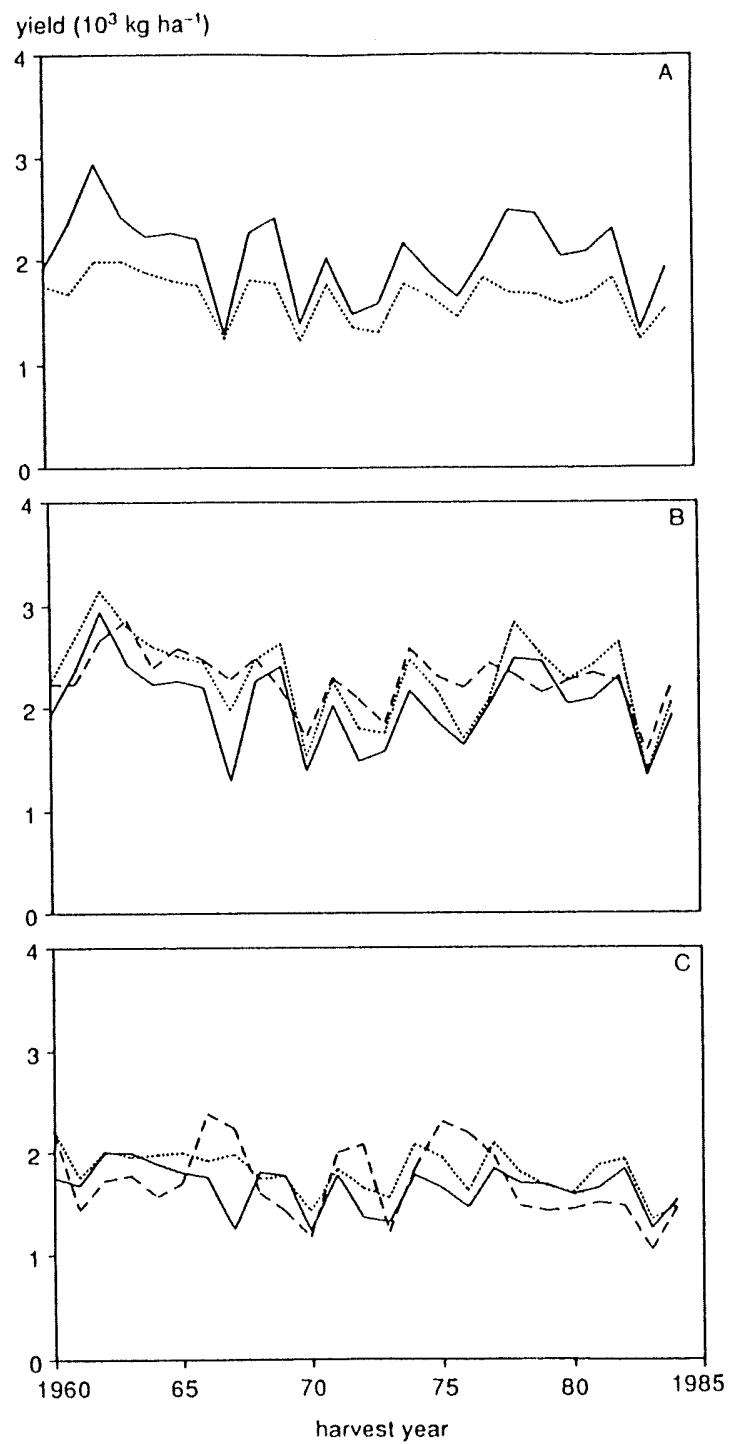

Fig. 4. Effect of using daily and average weather data on simulated potential and waterlimited production in Los Baños. A, simulated potential (solid line) and water-limited (dotted line) production using daily weather dala. B. simulated potential production using daily data (solid line) and monthly (dottec line) or seasonal averages (broken line). C, simulated water-limited production using daily data (solid line) and monthly (dotted line) or a seasonal averages (broken line). 
1 month were used, only $0 \cdot 1-0 \cdot 2$ ton/ha (Fig. 4 C). The use of seasonal averages resulted in both over- and underestimation of simulated yield and variability increased.

For both production levels only small differences were found in simulated yield using climatic averages based on different intervals (Table 4).

\section{DISCUSSION}

When precipitation is left out of consideration, weather in the mediterranean and humid tropics is intuitively far more constant than the weather in the temperate maritime climates. This impression is not in accordance with the deviations shown in Table 2. Only for Los Baños were deviations in temperature importantly smaller than the ones calculated for Wageningen. However, it should be realised that in Table 2 the deviation during the growing season is given. The growing season in Israel and the Philippines takes place in the winter period and in The Netherlands in the summer season. Based on Table 2 it can be concluded that weather in the summer in The Netherlands is as variable as the weather in the Israel and Philippine winter.

In general crops are grown in the season in which rain falls. Due to the existence of dry and rainy days in these seasons large variation in radiation occurs on successive days (clouds!) and on most locations also in temperature. When crops are grown under exclusive irrigation in a dry season the deviation is likely to be smaller. Since this is not a common practise in agriculture, the effect of using average values in this situation is not studied.

Besides the day-to-day variability of the weather most weather variables show a certain course during the year (e.g. low temperatures in winter and high temperature in summer). When seasonal averages are used this trend in lost, leading to a larger deviation from the daily values than the climatic averages in which this trend is retained.

Since the large variability in weather existed at all three sites, it is not surprising that the use of averages influenced the simulation results everywhere. The effect of using averages as input depended on the length of the averaged interval and the production level.

\section{Potential production}

The potential production is only determined by temperature and radiation. Radiation drives the photosynthesis and temperature determines 
development of the crop. Correct simulation of development is vital, since the effect of certain weather conditions on crop growth can vary with stage of development. Above the threshold value, the effect of temperature on development rate is linear. When average values over short periods are used, development of the crop is often not affected. In those cases yield is overestimated because of overestimation of photosynthesis (Fig. 1A) and annual variation in yield is remained. When averages over a complete season are used, temperature is overestimated in the early season and underestimated in the late season. This affects individual development stages (vegetative period becomes shorter and grain filling longer). On sites with a large range in temperature during the season (Wageningen \& Migda, Table 2) the effect of using seasonal averages on simulated yield is therefore far different from the effect of averages over shorter periods (Figs. 2B, 3B). In Los Baños, where temperature is more or less constant over the season, the effect is much smaller (Fig. 4B).

At Wageningen the similarity between average yield with seasonal averages and average simulated yield with daily data is a coincidence. It cannot be concluded that use of seasonal averages gives a better result than averages over shorter intervals. For spring wheat, in The Netherlands, a long vegetative period is important. Reduction of this period leads to a yield decline (Nonhebel, 1993a). When seasonal averages are used, the overestimation of the yield due to averaging radiation is counteracted by the reduction of the vegetative period (due to higher temperatures in spring). For other crops or on sites with a smaller range in temperature through the season (Los Baños) this effect will not occur (Table 3).

When climatic averages based on short intervals (days, 10 days or months) were used, the simulated yields were of the same order of magnitude as averaged yields with 10-day or monthly values. Thus when one is only interested in average potential yield in a region, climatic averages can be used as input, although it should be kept in mind that the simulated yield is higher than the average yield with daily data. However, one often wishes to compare production possibilities in different regions. The ranking of yields among the study sites is not similar for daily values and climate averages (Tables 3 and 4). The differences in average potential yield between Wageningen and Los Baños based on daily values is 5.0 ton/ha, but based on climatic averages (on a monthly basis) it is $6 \cdot 1$ ton/ha.

When the annual variability of the yield is a point of interest the average data over months can be used (but yields levels remain higher than when daily data are used). The use of averages over shorter periods than 1 month ( 10 days) did not improve the simulation results either in 
average yield level or in annual variability. So the greater effort and expense coupled with handling and obtaining three times as many data are not worth the trouble. When averages over longer periods than 1 month are used, the seasonal trend in weather is lost, which can influence simulations results.

\section{Water-limited production}

As mentioned before the distribution of precipitation has a large effect on the amount of water available for uptake by the roots. The effect of averaging weather data on water-limited yields depends on the circumstances. In dry conditions averaging precipitation leads to an increase of water losses due to greater evaporation from the top soil layer. These effects arc seen clearly in the effects of averaging weather data on the water-limited yiclds. For The Netherlands average weather data over short periods led to underestimation of the yields in the dry years (1957, $1959,1973,1976,1983)$. Use of average weather for the arid circumstances in Migda led to underestimation of yields in all years. Under wet conditions, averaging precipitation had no effect on water shortage because even when evaporations losses increased there was still enough water for growth. In these cases the effects were the same as for the potential situation: averaging weather data led to overestimation of the yield. In seasons in which only a small number of days with water shortage exists, these effects level out. On the dry days growth is underestimated and on wet days it is overestimated, resulting in only a very small deviation from yield simulated with daily data. These effects are evident in most years for the Philippines and in the a number of years in The Netherlands (Figs. 2C, 4C).

In The Netherlands and the Philippines water is only limiting a few weeks at the end of the growing season. In the early season a water surplus exists. When averages over longer periods are used, this early season surplus compensates for the shortage at the end. Hence there are fewer years with water shortage. In The Netherlands only in 1976 was dry when seasonal averages were used (Fig. 2C).

So the use of average values in the water-limited situation has an effect on the variability of the yields. In regions in which dry and wet years occur, the variability increases, since use of averages over short periods results in overestimation of the yield in wet years and underestimation in dry years. In regions in which yield is mainly determined by the amount of water available, use of averages reduces variability. Even relative wet years become dry due to increased evaporation losses (Israel, 1964, 1980).

In Israel another process was affected by precipitation. In the model 
the crop starts to growth as soon as water is available. In 1966 first winter rains only occurred at the end of December. Use of monthly averages of precipitation implied that the 1 st of December was already a wet day, so the simulated growing season started nearly one month too early, resulting in yield increase in that particular season (Fig. 3C, harvest in 1967!).

The importance of rainfall distribution on the amount of water available for uptake by the roots is recognized by many authors. Therefore, rainfall generators are often used when only average values are available (van Keulen et al., 1987; van Lanen et al., 1992). These routines simulate a rainfall pattern, through which wet and dry days are created (Geng et al., 1986). The use of daily precipitation values in combination with averages for the other weather variables is also practised (Lopez-Tirado \& Jones, 1991). Both methods reduce the evaporation losses in comparison with the average rainfall data and will lead to better simulation results in arid conditions.

\section{CONCLUDING REMARKS}

It can be concluded that, for the model used in here, use of average weather data leads to other simulation results than use of daily data. When averages are used, potential production is overestimated and water-limited production is overestimated in wet years and underestimated in dry years.

There are two causes for this deviation in simulation results. First, the crop model used contained non-linear relations through which average input does not result in average output. Second, on locations studied a large variability in weather existed from day to day, through which daily data differed from the average value.

Most weather-crop growth relations are non-linear, so most crop growth models will contain non-linear functions. Crops are generally grown in that part of the year in which it rains. The existence of dry and rainy days leads to a large variability in weather during the growing seasons all over the world. Effects comprisable to those found in this paper can therefore be expected for other crop growth simulation models.

\section{ACKNOWLEDGEMENTS}

This work was partly funded by the Ministry of Housing, Physical Planning and Environment (VROM) of the Dutch government and partly by 
the Commission of the European Communities (EV4C-0019-NL). I thank C. T. de Wit and J. Goudriaan for discussion.

\section{REFERENCES}

Adams, R. M., Rosenzweig, C., Peart, R. M., Ritchie, J. T., McCarl B. A., Glyer, J. D., Curry, R. B., Jones, J. W., Booth, K. J. \& Hartwell Allen, L. Jr (1990). Global climate change and US agriculture, Nature, 345, 219-223.

Aggarwal, P. K., Liboon, S. P. \& Morris, R. A. (1987). A review of wheat research at the International Rice Research Institute. IRRI Research Papers Serie's No. 142, IRRI, Philippines.

Aggarwal, P. K. \& Penning de Vries F. W. T. (1989). Potential and waterlimited wheat yields in rice based cropping systems in southeast Asia. Agricultural Systems, 30, 49-69.

Buishand, T. A. \& Velds, C. A. (1980). Neerslag en verdamping. KNMI, de Bilt, The Netherlands, $206 \mathrm{pp}$. (in Dutch).

Cooter, E. L. (1990). The impact of climate change on continuous corn production in the southern USA. Climatic Change, 15, 53-82.

Van Diepen, C. A., de Koning, G. H. J., Reinds, G. J., Bulens, J. F. \& van Lanen H. A. J. (1990). Regional analysis of physical crop production in the European community. In The Greenhouse Effect and Primary Productivity in European Agro-ecosistems, eds Goudriaan, J., van Keulen, H. \& van Laar, H. H., pp. $74-79$.

Flores, J. F. \& Balagot, V. F. (1969). Climates of the Philippines. In Climates of Northern and Eastern Asia. World Survey of Climatology, Vol 8, ed. Arakawa, H. Elsevier, Ansterdam, pp. 159-213.

Geng, S., Penning de Vries, F. W. T. \& Supit, I. (1986). A simple method for generating daily rainfall data. Agricultural and Forest Meteorology, 36, $363-376$.

Hodges, T., Botner, D., Sakamoto, C. \& Hays Houg, J. (1987). Using the CERES maize model to estimate production for the US cornbelt. Agricultural and Forest Meteorology, 40, 293-303.

Jansen, D. M. (1990). Potential rice yields in future weather conditions in different parts of Asia, Neth. J. Agri. Science, 38, 661-680.

Jones, C. A. \& Kiniry, J. R. (1986). CERES Maize: A Simulation Model of Maize Growth and Development. Texas A\&M University Press, College Station, TX, USA, 194 pp.

de Jong, J. A. (1986). De teelt van gramen. De Jong, Drachten, The Netherlands (in Dutch), 208 pp.

van Keulen, H. (1975). Simulation of water use and herbage growth in arid regions. Pudoc, Wageningen, The Netherlands, $175 \mathrm{pp}$.

van Keulen, H. \& Seligman, N. G. (1987). Simulation of Water Use, Nitrogen Nutrition and Growth of a Spring What Crop. Simulation Monographs, Pudoc, Wageningen, The Netherlands, $310 \mathrm{pp}$.

van Keulen, H. \& de Milliano, W. A. J. (1984). Potential wheat yields in Zambia-a simulation approach. Agricultural Sistems, 14, 171-192.

van Keulen, H., Berkhout, J. A. A., van Diepen, C. A., van Heemst, H. D. J., 
Janssen, B. H., Rappoldt, C. \& Wolf, J., (1987). Quantitative land evaluation for agro-ecological characterization. In Agricultural Environments. Characterization, Classification and Mapping. ed. Bunting, A. H., C. A. B. International, Wallingford, UK, pp. 185-196.

Können, G. P. (1983). Het weer in Nederland, Thieme, Zutphen, The Netherlands (in Dutch), $144 \mathrm{pp}$.

van Lanen, H. A. J., van Diepen, C. A., Reinds, G. J., de Koning, G. H. J., Bulens, J. D. \& Bregt, A. K. (1992) Physical land evaluation methods and GIS to explore the crop growth potential and its effects within the European communities. Agricultural Systems, 39, 307-28.

Lopez-Tirado, Q. \& Jones, J. G. W. (1991). A simulation model to assess primary production and use of Bouteloua gracilis grasslands. Part 2. Experimentation. Agricultural Sistems, 35, 209-227.

Nonhebel, S. $(1993 a)$. The effect of changes in temperature and $\mathrm{CO}_{2}$ concentration on spring wheat yields in The Netherlands. Climatic Change, 24, 311-29.

Nonhebel, S. (1993h). The importance of weather data in crop growth simulation models and assessment of climatic change effects. PhD thesis, Agricultural University, Wageningen, The Netherlands.

Oldeman, L. R. \& Frère, M. (1982). A Study' of the Agroclimatology of the Humid Tropics of Southeast Asia. FAO, Rome, ltaly.

Ritchie, J. T. \& Otter, S., (1984). CERES Wheat User-orientated Wheat Yield Model. Agristar Publ. Ym-US-04442-JSC-18892, Michigan Statc University, MI, USA.

Spitters, C. J. T., van Kralingen, D. W. G., van Keulen, H. (1989), A simple and universal crop growth simulator: SUCROS 87. In Simulation and systems management in crop prolection, eds Rabbinge, R., Ward, S. A. \& van Laar, H. H. Simulation Monographs, Pudoc, Wageningen, The Netherlands, pp. 145-181.

Taha, M. F., Harb, S. A., Nagib, M. K. \& Tantawy, A. H. (1981). The climate of the Near East. In Climates of Southern and Western Asia: World Survey of Climatology, Vol. 9, eds Takahasi, K. \& Arakawa, H. Elsevier, Amsterdam, pp. 183-255.

Whisler, F. D., Acock, B., Baker, D. N., Fye, R. E., Hodges, H. F., Lambert, J. R., Lemmon, H. E., McKinion, J. M. \& Reddy, V. R. (1986). Crop simulation models in agronomic systems. Advances in Agronomy, 40, $141-208$

Wilks, D. S. (1988). Estimating the consequences of $\mathrm{CO}_{2}$-induced climatic change on North American grain agriculture using General Circulation Model Information. Climatic Change, 13, 19-42.

de Wit, C. T. \& Penning de Vries, F. W. T. (1982). La synthèse et la simulation des systèmes de production primaire. In La Productivité des Pâturages sahelien, eds Penning de Vries, F. W. T. \& Djiteye, H. A. Agricultural Research Reports No. 918, Pudoc, Wageningen, The Netherlands, pp. 23-25. 